\title{
CONTROLE JUDICIAL DE POLÍTICAS PÚBLICAS: INTERDIÇÃO DE CADEIAS PÚBLICAS
}

\author{
Élio Boing ${ }^{1}$
}

BOING, E. Controle judicial de políticas públicas: interdição de cadeias públicas. Rev. Ciênc. Juríd. Soc. UNIPAR. Umuarama. v. 20, n. 2, p. 295-309, jul./ dez. 2017.

RESUMO: O presente artigo analisa a possibilidade de intervenção do Poder Judiciário na implementação de políticas públicas para a correção dos graves problemas que afetam as cadeias públicas. Assim, estuda-se o comportamento da jurisprudência acerca do tema e estabelece as condições necessárias que autorizam a intervenção judicial.

PALAVRAS-CHAVE: Controle judicial; Estabelecimento carcerário; Políticas públicas.

\section{INTRODUÇÃO}

Anos de abandono e descaso levaram o sistema prisional brasileiro a uma situação insustentável, exigindo medidas urgentes para garantir o mínimo necessário de dignidade aos presos. Neste contexto, surge o controle judicial de políticas públicas como atividade suplementar, obrigando o administrador público a tomar providências para garantir os direitos fundamentais das pessoas que foram levadas ao cárcere.

As decisões judiciais em matéria de estabelecimentos prisionais demonstravam uma resistência em se interferir no âmbito do poder discricionário do administrador público. Porém, em recente decisão, o Supremo Tribunal Federal atribuiu legitimidade ao Poder Judiciário para impor obrigação de fazer ao administrador quando se tratar de questões que envolvem a dignidade do preso.

Por fim, a intervenção judicial deve respeitar limites que buscam manter o equilíbrio entre os poderes que são independentes e harmônicos entre si. O respeito às balizas legais confere legitimidade à atuação do magistrado quando interfere no âmbito das discricionariedades administrativas e tornam as obrigações realizáveis no plano fático.

DOI: $10.25110 /$ rcjs.v20i2.2017.6745

${ }^{1}$ Discente no programa de Mestrado em Direito Processual e Cidadania da Unipar - Universidade Paranaense. Umuarama, Paraná, Brasil. E-mail: boing74@hotmail.com. 


\section{MEIO AMBIENTE CARCERÁRIO}

O meio ambiente saudável é uma preocupação que vem crescendo ao longo dos anos. Este fenômeno é observado em diversos países e tem como consequência o surgimento de acordos internacionais e legislações cada vez mais protetivas. A Constituição Federal, seguindo a tendência de proteção ambiental, garantiu a todos o direito a um ambiente ecologicamente equilibrado que possibilite uma vida saudável (BRASIL, 1988). Esta previsão constitucional é considerada pela doutrina e reconhecida pelo Supremo Tribunal Federal como direito fundamental.

A expressão meio ambiente não se refere apenas ao meio ambiente natural, ou seja, aquele facilmente identificado pela fauna e flora. É muito mais abrangente e engloba o meio ambiente cultural, artificial e do trabalho. O cultural constitui-se "representado pelo patrimônio culturalmente considerado para uma pequena região, um país ou, até mesmo, para todo o mundo" (SILVA, 2015, p. 26). O trabalho consiste em todos os aspectos da atividade laboral, que garantem as condições dignas do trabalho, seja em relação a limpeza adequada, barulho dentro dos limites, condições de asseio do local, dentre outros. Por fim, tem-se o meio ambiente artificial que 'se constitui de tudo o que foi construído pelo homem, retratando principalmente a vida em centros urbanos.

A cadeia pública se insere no ambiente artificial, uma vez que se trata de obra construída e idealizada pelo ser humano. Alguns afirmam existir um meio ambiente misto no qual estaria inserida a realidade do cárcere, pois reuniria aspectos do meio ambiente natural, cultural e artificial. Assim:

O ambiente carcerário é composto pelo conjunto arquitetônico, condições de higiene, do ar, da água, da alimentação, pelo acesso a serviço psicológico, condições de trabalho e recreação, ou seja, é aquele microambiente prisional composto por todos os elementos afetos direta e indiretamente aos que se sujeitam ao cárcere, salvo aqueles relacionados ao meio ambiente do trabalho, o qual é tratado de forma separada (SILVA, p. 68).

Constata-se, portanto, que as condições ambientais recebem a tutela constitucional e constituem direito fundamental de todo o cidadão. Este direito pode ser exercido de forma coletiva ou por meio de ações individuais, com a finalidade de obrigar o Estado a garantir um ambiente equilibrado e saudável.

A dificuldade que surge é definir o que seria um meio ambiente carcerário equilibrado diante da condição legal imposta ao recluso de cerceamento de sua liberdade. O recluso abrigado em cadeia pública é aquele sobre o qual recai uma prisão provisória, ou seja, a prisão temporária, em flagrante delito ou 
preventiva. Possuem como única limitação o cerceamento de seu direito de locomoção, estando suspensa por determinação judicial a sua liberdade. Mantém os demais direitos, constitucionalmente garantidos a todos os cidadãos, incluindo o meio ambiente carcerário equilibrado.

Dessa forma, o recluso mantém o direito à saúde, educação, respeito à integridade física e moral, dentre outros. Se o Estado retira do convívio social uma pessoa deve lhe garantir a preservação de seus direitos, inobstante a gravidade do crime cometido. Manter o meio ambiente carcerário adequado e não atentar à dignidade do detento é responsabilidade do Estado. Sempre que esta premissa não for observada será necessária a atuação do Poder Judiciário para fazer valer as garantias do recluso.

\section{REALIDADE BRASILEIRA}

O sistema carcerário nacional é composto por diversos estabelecimentos penais. As penitenciárias são destinadas ao recolhimento de presos condenados definitivamente a penas privativas de liberdade com cumprimento em regime fechado. As cadeias públicas abrigam os presos provisórios, ou seja, aquele sob os quais não existe uma sentença penal condenatória definitiva. Colônias penais agrícolas ou industriais destinam-se aos condenados que estejam cumprindo penas no regime semiaberto. As casas de albergados abrigam aqueles que cumprem pena em regime aberto ou penas restritivas de finais de semana. Por fim, os hospitais de custódia são destinados às pessoas submetidas às medidas de segurança.

A legislação pátria prevê uma série de direitos às pessoas que cumprem medidas restritivas de liberdade. Essas garantias, em geral, vêm sendo desrespeitadas e os estabelecimentos penais revelam-se ineficientes na tarefa de ressocialização e reintegração do indivíduo na sociedade. Verifica-se que uma parcela expressiva dos egressos retoma a atividade criminosa após o cumprimento de sua pena. Em muitos casos a prisão confere uma especialização em outras atividades criminosas, em razão dos contatos realizados com os mais diversos tipos de criminosos.

A capacidade instalada do sistema carcerário não tem atendido às necessidades. O Anuário de Brasileiro de Segurança Pública (2015, p. 68) aponta que no ano de 2014 existiam 579.423 pessoas cumprindo penas em estabelecimentos penais. No entanto, todo o sistema carcerário disponibilizava somente 375.892 vagas, ou seja, uma necessidade de criação de 203.531 vagas. Esta realidade poderia ser agravada se os mandados de prisão em aberto fossem cumpridos. Dados do Banco Nacional de Mandados de Prisão, mantido pelo Conselho Nacional de Justiça (2016), informam que existem 509.289 mandados de prisão aguardando para serem cumpridos. Esta realidade não tem permitido às penitenciárias to- 
dos os presos condenados definitivamente. Uma parcela dos reclusos permanece cumprindo a pena no âmbito da cadeia pública, a qual não possui estrutura adequada e, via de regra, mantém os reclusos em condições subumanas.

Todos esses fatores estruturais, como também a má-alimentação dos presos, seu sedentarismo, o uso de drogas, a falta de higiene e toda a lugubridade da prisão fazem com que o preso que ali adentrou numa condição sadia de lá não saia sem ser acometido de uma doença ou com sua resistência física e saúde fragilizadas (ASSIS, 2007, p. 75).

As deficiências do sistema carcerário geram uma dupla penalidade ao condenado, ou seja, além da restrição à sua liberdade, a degradação de seu estado de saúde durante a sua permanência no cárcere. Estima-se que um quinto dos presos brasileiros sejam portadores do HIV (Human Immunodeficiency Virus), decorrente do uso de drogas, homossexualismo ou violência sexual (ASSIS, 2007).

Esta constante violação a princípios constitucionais, notadamente o da dignidade da pessoa humana e do meio ambiente equilibrado, vem exigindo uma nova postura do Poder Judiciário. Em decorrência da nova ordem constitucional e do entendimento que os princípios constitucionais não são normas meramente programáticas, avolumaram-se decisões judiciais de interdição de cadeias públicas por não estarem atendendo ao mínimo necessário os direitos dos detentos. Essas decisões judiciais, além de não permitirem a inserção de novos detentos, determinam algumas obrigações de fazer ao administrador público, impondo multas diárias para o caso de descumprimento.

É este o ponto que, a partir de casos concretos, o presente artigo pretende analisar, evidenciando as consequências das decisões e sua efetividade diante da realidade vivenciada. Além disso, busca estabelecer os critérios legais que devem balizar a decisão do julgador, sob pena de privilegiar questões locais em detrimento do problema como um todo.

\section{POLÍTICAS PÚBLICAS}

O tema políticas públicas vem ocupando um grande espaço nos últimos tempos. Os debates aprofundam-se e fomentam cada vez mais a participação da sociedade na definição das prioridades a serem executadas pelo Estado. Este fenômeno é reflexo da conquista de liberdades individuais decorrentes da redemocratização e da nova ordem constitucional. Influencia, também, a facilidade de acesso à informação que contribui para o desenvolvimento do espírito crítico e oportuniza meios de cobrança e participação mais eficazes. 
Trata-se de assunto da alçada da ciência política, porém não se limita a esta área do conhecimento, possuindo reflexos em várias disciplinas, teorias e modelos analíticos (SOUZA, 2006). Assim, pode ser objeto da sociologia, economia, administração e, em razão do controle judicial das políticas públicas, do direito.

Para se conceituar políticas públicas não se pode deixar de considerar o tema do controle dos recursos financeiros disponibilizados ao Estado para a consecução do bem comum (SILVA, 2013). Neste sentido, pode se definir política pública como sendo "o campo do conhecimento que busca, ao mesmo tempo, ‘colocar o governo em ação' e/ou analisar essa ação (variável independente) e, quando necessário, propor mudanças no rumo ou curso dessas ações (variável dependente)" (SOUZA, 2006, p. 26). Constitui-se em ação dos governos para resolver necessidades públicas, ferramenta indispensável para a concretização dos direitos constitucionais fundamentais.

A formulação, implementação e execução requerem ampla participação da sociedade. A participação inicia-se pela escolha de representantes por meio do voto, aos quais é repassado parcela de poder para decidir em nome do povo. Infelizmente o país vive uma crise de representação, uma vez que os eleitos não reproduzem no seu atuar o discurso proferido no momento de pedir o apoio da população. Em geral, defendem o seu próprio interesse e a de seus financiadores, normalmente grandes corporações.

Por outro lado, tem se observado uma sociedade mais atuante e organizada, que cobra coerência do governo e conquista espaço de participação no jogo político. Surgem fenômenos que fomentam a participação direta da sociedade, como, por exemplo, os orçamentos participativos adotados em alguns locais. Os projetos de lei de iniciativa popular também representam este novo fenômeno, pois refletem o anseio de uma grande parcela da sociedade que propõem aos seus representantes a adoção de determinado caminho a ser percorrido.

O processo de escolha de prioridades é um processo com ampla discricionariedade. Os representantes do povo adotam opções sobre a aplicação dos recursos públicos através da formulação, gestão e implementação de políticas públicas. É bem verdade que esta discricionariedade é limitada pela Constituição Federal e por leis infraconstitucionais, as quais também são resultados de processos democráticos de escolha por parte do legislador. Assim, a título de exemplo, o administrador se vê obrigado a destinar parte orçamentária para a saúde e educação, além do que se vê limitado pela Lei de Responsabilidade Fiscal.

A adoção de políticas públicas cria para o Estado uma obrigação jurídica positiva no sentido de implementar ações para garantir o seu efetivo cumprimento, principalmente na concretização dos direitos fundamentais. Esta obrigação encontra fundamento no neoconstitucionalismo que impõe à Administração Pú- 
blica geri-las em consonância com os princípios constitucionais (SILVA, 2013).

Neste ponto surge a possibilidade de se controlar judicialmente a formulação e gestão de políticas públicas, uma vez que estas devem atender aos princípios constitucionais e quando deles desbordam são irregulares e devem ser corrigidas. A omissão da Administração Pública em formular políticas públicas direcionadas a efetivar os direitos fundamentais também pode ser objeto de controle por parte do Poder Judiciário. Dessa forma, permite-se a interdição de cadeias públicas e as determinações para que o Estado promova as alterações necessárias com o fim de garantir o direito fundamental dos reclusos.

\section{CONTROLE JUDICIAL DE POLÍTICAS PÚBLICAS}

Nos últimos tempos tem-se observado a atuação do Poder Judiciário em temas de ampla repercussão social e um aumento efetivo das questões que são levadas ao crivo de uma decisão judicial. Este fenômeno decorre da redemocratização do país após um período de exceção. É consequência direta da nova ordem constitucional que garantiu um judiciário independente e autônomo, bem como estabeleceu um amplo rol de direitos e garantias individuais, facilitando o acesso de todos à justiça. No mesmo sentido, estabeleceu um controle de constitucionalidade que concede ao magistrado um enorme campo de atuação (BARROSO, 2009, p. 19-20).

O fenômeno da judicialização conduz a novas práticas e novas formas de se aplicar o direito. Nesta esteira surge o ativismo judicial que pode ser visto sob dois enfoques, conforme afirma Cesar Cipriano de Fazio (2014, p. 110):

Sob um primeiro enfoque, mais facilmente admissível nos limites do sistema jurídico, a doutrina considera como postura ativista a interpretação das leis e apreensão dos valores legais e constitucionais para a solução juridicamente fundamentada dos casos concretos, com visão progressista, evolutiva e até "reformadora" (expressão que quase transborda para o segundo enfoque), segundo a qual o juiz não figura no âmbito da mera subsunção ou aplicação da lei, tampouco como mera "boca da lei", mas nesta encontra seus limites.

Note-se que o ativismo judicial pressupõe uma maior interferência do Poder Judiciário nas competências dos outros poderes, assumindo funções que originariamente não lhe pertenciam. Nesta seara, atua diante do enfraquecimento e inoperância dos poderes executivo e legislativo em cumprirem o seu papel constitucional. Barroso $(2009$, p. 22) afirma que o ativismo se manifesta através das seguintes posturas: 
(i) a aplicação direta da Constituição a situações não expressamente contempladas em seu texto e independentemente de manifestação do legislador ordinário; (ii) a declaração de inconstitucionalidade de atos normativos emanados do legislador, com base em critérios menos rígidos que os de patente e ostensiva violação da Constituição; (iii) a imposição de condutas ou de abstenções ao Poder Público, notadamente em matéria de políticas públicas.

A imposição de condutas ao administrador público em matérias de políticas públicas é o tema central deste estudo, constituindo-se em uma clara postura ativista por parte do Poder Judiciário.

O debate doutrinário acerca do ativismo judicial segue duas correntes: procedimentalista e substancialista. A primeira nega legitimidade a posturas ativistas e a segunda entende pela necessidade do controle judicial das políticas públicas.

Os procedimentalistas negam autorização para que o judiciário invada as competências do Poder Executivo e Poder Legislativo, afirmado que esta conduta afeta gravemente o princípio da separação dos poderes. Para formular e gerir políticas públicas os poderes políticos recebem a investidura do sufrágio universal, possuindo a legitimidade para sua atuação e a intervenção judicial fere o processo democrático. A atuação do Poder Judiciário deve se resumir a garantir a participação democrática e livre. A atuação contramajoritária pode levar à tirania ou a judiocracia (SILVA 2013).

Anderson Vichinkeski Teixeira (2012, p. 42) adverte que o problema vai além da simples invasão de competências e da harmonia entre os poderes. Trata-se de uma confusão conceitual do direito e da política, justificando que:

Estamos diante de uma confusão conceitual e funcional entre Direito e Política. O ativismo judicial é apenas um dos sintomas mais flagrantes de que as sociedades de massa da era pós-moderna não se satisfazem mais com as prestações de serviços públicos e tutela de direitos individuais ainda nos moldes do Estado moderno; este se revela incapaz de lidar com as necessidades e demandas que crescem em um ritmo frenético no seio da sua própria população. A Política encontra-se acometida pela burocracia - e progressiva burocratização - do Estado, pela insuficiência regulatória, pelo descompasso frente à realidade social e pelo déficit de legitimidade que as democracias ocidentais apresentam quando comparadas com os ideais sociais e expectativas populares que suas respectivas sociedades projetam. Mais do que uma discussão acerca da separação dos poderes, o ativismo judicial nos propõe uma discussão acerca do que atualmente representam os limites entre Direito e Política. 
Dessa forma, para esta corrente, o Poder Judiciário carece de legitimidade democrática para interferir na formulação, gestão e implementação de políticas públicas, não podendo limitar a discricionariedade dos agentes políticos, os quais estão autorizados democraticamente a fazer escolhas. As decisões contramajoritárias ferem a vontade popular e colocam o direito "como 'segunda e inadequada instância do jogo político', pervertendo a representação, em evidente prejuízo à circularidade do poder e à contingência própria do regime democrático" (FAZIO, 2014, p. 110).

$\mathrm{Na}$ contramão desses argumentos surge a corrente substancialista que defende o ativismo judicial como necessidade para se implementar os direitos fundamentais. Afirmam que o juiz não deve ser um mero aplicador das leis, mas sim um agente de transformação da sociedade e fomentador da democracia participativa. Constata-se no plano prático que a lei tem origens em um processo legislativo majoritário que nem sempre busca a justiça e a igualdade (SILVA, 2013).

O denominado ativismo judicial tem a finalidade extrair o máximo possível da Constituição Federal sem limitar o campo criativo do direito. Constitui-se no exercício de um poder-dever, uma vez que os casos são deduzidos em juízo e exigem um pronunciamento judicial (FARIAS, 2014). Dworkin (2005, p. 26) investiga a qualidade das decisões judiciais e legislativas expressando que "não consigo imaginar em que argumentos se poderiam pensar para demonstrar que as decisões legislativas sobre direitos têm mais probabilidade de serem corretas que decisões judiciais".

A questão da legitimação do Poder Judiciário para praticar o ativismo judicial decorre de sua investidura através de concurso público e de que sua função é a proteção da Constituição Federal e a defesa dos direitos fundamentais.

\subsection{INTERDIÇÃO DE CADEIAS PÚBLICAS}

A interdição de cadeia pública encontra previsão legal na Lei de Execução Penal (Lei n ${ }^{\circ}$ 7.210, de 11 de junho de 1984) em seu art. 66, verbis:

Art. 66. Compete ao Juiz da execução:

....

VII - inspecionar, mensalmente, os estabelecimentos penais, tomando providências para o adequado funcionamento e promovendo, quando for o caso, a apuração de responsabilidade;

VIII - interditar, no todo ou em parte, estabelecimento penal que estiver funcionando em condições inadequadas ou com infringência aos dispositivos desta Lei; 
Note-se que o dispositivo legal autoriza o magistrado a interditar estabelecimentos penais que estejam em desacordo com a lei. Ocorre que a jurisprudência tem demonstrado que a maioria das Ações Civis Públicas, além da interdição, impõem obrigação de fazer ao administrador público. Estas obrigações consistem em reformas, ampliações, transferências de presos, designação de contingente policial, dentre outras. Constitui-se em uma intervenção no poder discricionário do administrador público e na gestão de políticas públicas. Muitas decisões judiciais de primeira instância impõem ao Estado estas obrigações, porém a tendência dos tribunais era a reforma da decisão, conforme se vê no seguinte julgado:

APELAÇÕES CÍVEIS/REEXAME NECESSÁRIO - AÇÃO CIVIL PÚBLICA - PRELIMINARES - REJEITADAS - ESTADO DE MINAS GERAIS - OBRIGAÇÃO DE FAZER - REALIZAÇÃO DE OBRAS E REFORMAS DE ADEQUAÇÃO EM CADEIA PÚBLICA - MÉRITO ADMINISTRATIVO - INGERÊNCIA DO JUDICIÁRIO - INDEVIDA - SUPERLOTAÇÃO DA CADEIA - TRANSFERÊNCIA DE PRESOS PARA ESTABELECIMENTO ADEQUADO - POSSIBILIDADE - MULTA DIÁRIA - MINORAÇÃO - SENTENÇA PARCIALMENTE REFORMADA.

(TJ-MG - AC: 10220140001177002 MG, Relator: Hilda Teixeira da Costa, Data de Julgamento: 09/06/2015, Câmaras Cíveis / $2^{\mathrm{a}}$ CÂMARA CÍVEL, Data de Publicação: 12/06/2015)

O Supremo Tribunal Federal seguia a mesma linha de resistência à possibilidade de impor obrigação de fazer ao Estado em relação às cadeias públicas, argumentando que a definição de políticas públicas nesta seara é ato discricionário do administrador, não comportando, portanto, a intervenção do poder judiciário, conforme se observa na seguinte decisão:

APELAÇÕES CÍVEIS. AÇÕES CIVIS PÚBLICAS. OBRIGAÇÃO DE FAZER. ILEGITIMIDADE PASSIVA DO ESTADO AFASTADA. REFORMA DE CENTRO DE REINTEGRAÇÃO SOCIAL E CADEIA PÚBLICA. VIOLAÇÃO AOS PRINCÍPIOS DA SEPARAÇÃO DOS PODERES E DA DISCRICIONARIEDADE ADMINISTRATIVA. MANUTENÇÃO DE POLICIAIS MILITARES NO PRESÍDIO. VIOLAÇÃO À REGRA DO CONCURSO PÚBLICO. SEGURANÇA DO FÓRUM. DECRETO JUDICIÁRIO n ${ }^{\circ}$ 2923/2011. (STF - RE: 827809 GO, Relator: Min. ROBERTO BARROSO, Data de Julgamento: 12/09/2014, Data de Publicação: DJe190 DIVULG 29/09/2014 PUBLIC 30/09/2014) 
Ocorre que Corte Suprema recentemente mudou este entendimento ao dar provimento ao Recurso Extraordinário 592.581 do Rio Grande do Sul de relatoria do Ministro Ricardo Lewandowski, cujo julgamento se deu em 13 de agosto de 2015.

O Ministério Público ajuizou ação civil pública em razão da precariedade das instalações físicas da Casa do Albergado de Uruguaiana/RS, as quais violariam o direito constitucional de integridade física e moral das pessoas que cumprem pena naquele estabelecimento penal. A sentença de primeira instância acatou os argumentos do Ministério Público e determinou ao governo daquele Estado Membro a obrigação de executar obras, com o fim de adequar as instalações de forma a não ferir os direitos dos presos.

Atendendo à jurisprudência dominante à época, o Tribunal de Justiça reformou a decisão argumentando que se trata de direito social do preso, norma meramente programática, a qual não possui caráter impositivo, não podendo o Poder Judiciário interferir na discricionariedade administrativa, se aplicando ao caso a reserva do possível.

Inconformado com a decisão o Ministério Público recorreu e o Supremo Tribunal Federal, por unanimidade, contrariando a jurisprudência até então dominante, entendeu que é lícito e adequado a interferência do Poder Judiciário com a finalidade de preservar a dignidade das pessoas levadas ao cárcere. Diversamente do entendimento do Tribunal de Justiça gaúcho, asseverou o STF que o caso retrata violação a direito fundamental e não meramente social, possuindo caráter impositivo, não se tratando de norma constitucional meramente programática.

Esta decisão do STF é paradigmática e devido a sua relevância jurídica, política, social e econômica, foi proposta pelo relator e acatado pelos demais membros da Corte a repercussão geral. Assim, se fixou a seguinte tese de repercussão geral, tema 220:

É lícito ao Judiciário impor à Administração Pública obrigação de fazer, consistente na promoção de medidas ou na execução de obras emergenciais em estabelecimentos prisionais para dar efetividade ao postulado da dignidade da pessoa humana e assegurar aos detentos o respeito à sua integridade física e moral, nos termos do que preceitua o art. $5^{\circ}$, XLIX, da Constituição Federal, não sendo oponível à decisão o argumento da reserva do possível nem o princípio da separação dos poderes.

Este novo entendimento ainda não transitou em julgado, pois carece de julgamento de Embargos de Declaração interposto pelo estado do Rio Grande do Sul, porém, mesmo que acatado, pouco mudaria o entendimento do plenário do 
STF, uma vez que pede para que seja acrescido na decisão a expressão "desde que se evidencie um 'não fazer' comissivo ou omissivo por parte das autoridades estatais que coloque em risco, de maneira grave e iminente, os direitos dos jurisdicionados." Este recurso se fundamenta na ratio decidiendi, uma vez que o argumento fez parte da fundamentação no voto do relator.

Dessa forma, o entendimento passou a ser de que o Poder Judiciário pode intervir na gestão de políticas públicas e determinar obrigação de fazer ao Estado sempre que ocorrer violação ao princípio constitucional da dignidade da pessoa humana.

\subsection{CRITÉRIOS LIMITADORES DA INTERVENÇÃO JUDICIAL}

O primeiro limitador em relação à intervenção do Poder Judiciário na implementação de políticas públicas é a teoria da "reserva do possível". Ana Paula de Barcellos (2011, p. 276) afirma que "a expressão reserva do possível procura identificar o fenômeno econômico da limitação dos recursos disponíveis diante das necessidades quase sempre infinitas a serem por eles supridas."

No entanto, no caso em análise a tese de repercussão geral do Supremo Tribunal Federal proíbe a oposição da reserva do possível no caso em análise. Essa determinação é questionável, uma vez que o administrador público deve se ater aos recursos financeiros disponíveis e a decisão judicial que interfere nestas questões deveria indicar a fonte de recursos para materializar o que foi determinado, sob pena de criar uma obrigação que não dispõe de fonte financiadora. No mesmo sentido a ratio decidendi exposta no voto condutor informa que os recursos existem, uma vez que o Fundo Penitenciário Nacional possui vultosa quantia não utilizada (acima de dois bilhões de reais).

Os Estados-Membros também possuem os seus Fundos Penitenciários próprios. No Paraná este fundo não possui grandes valores financeiros, tendo como receitas no ano de 2014 a quantia de $\mathrm{R} \$ 4.287 .001,54$, destes valores apenas parte foi aplicada na melhoria do meio ambiente carcerário, gerando um superávit de R $\$ 2.924 .494,38$, sendo que $80 \%$ deste resultado financeiro foi repassado ao tesouro do Estado, não mais constituindo-se recursos do fundo (PARANÁ, 2016). É certo que se todos os recursos financeiros fossem aplicados, amenizaria um pouco a situação precária das cadeias públicas.

O Fundo Penitenciário Nacional está subordinado ao Ministério da Justiça e a liberação de seus recursos depende de convênios com as Unidades da Federação, além do que é resultado de anos de arrecadação e está sujeito a constantes contingenciamentos. Além disso, a liberação de recursos financeiros depende de vontade política e constitui-se em discricionariedade administrativa. Estes fatores limitam o acesso aos recursos financeiros do fundo, o que poderia 
ser corrigido se a decisão judicial determinasse o uso destes recursos.

Em contrapartida o voto condutor estabeleceu que a intervenção judicial deve buscar atender ao "mínimo existencial" da dignidade que o Estado tem que oferecer aos reclusos. A teoria do mínimo existencial constitui-se no "conjunto de circunstancias materiais mínimas a que todo homem tem direito; é o núcleo irredutível da dignidade da pessoa humana (BARCELLOS, 2002, p. 45)". A decisão judicial não pode ir além deste limite, ou seja, não poderia impor uma obrigação de fazer ao Estado que extrapole o argumento do mínimo existencial.

A questão que surge é o alcance deste mínimo existencial e quais intervenções judiciais o extrapolariam. O assunto possui uma elevada carga de subjetividade, somente podendo ser aquilatado diante de um caso concreto. É certo que a sentença não pode desconsiderar o contexto da realidade vivenciada no Brasil, sob pena de se criar maiores desigualdades quando a finalidade da intervenção judicial é estabelecer os parâmetros mínimos a serem atendidos. Assim, diante da realidade de déficit de vagas em estabelecimentos carcerários superiores a 200.000 e com o agravante de mais de 500.000 mandados de prisão a serem cumpridos, não seria razoável que se determinasse a ampliação de um estabelecimento que possui condições muito superiores a esta realidade.

A fundamentação racional e convincente da decisão judicial constitui-se em outro parâmetro limitador imposto ao magistrado, cuja necessidade será maior quanto maior for o ativismo judicial. A legitimação da decisão está na medida em que o magistrado consegue expor as razões que, no caso concreto, justificam a adoção de uma posição contramajoritária. "Não basta a invocação de princípios jurídicos, sendo necessária, inclusive, a justificação da competência decisória e a análise das consequências negativas da intervenção judicial em substituição ao legislador ou administrador" (FAZIO, 2014, p.113).

Deve se considerar que não é lícito ao Poder Judiciário amplamente implementar políticas públicas, devendo se ater a situações em que há um não fazer comissivo ou omissivo por parte do Estado, que represente risco grave e iminente aos direitos do recluso. Neste sentido, argumenta Cesar Cipriano de Fazio (2014, p. 114):

Aliás, consoante defendido pelas teorias jurídicas calcadas na argumentação, a lei, como concretização da "representação política", só pode ser substituída por uma "representação argumentativa" judicial na medida em que esta tenha suficiente poder de persuasão racional sobre a prevalência de determinado direito fundamental no caso concreto e também relativamente às suas bases materiais, fáticas, técnicas, políticas etc. ("ônus do regulador"). Essa atividade judicial, portanto, é complementar à do parlamento para manutenção da democracia e da ordem constitucional, observados ainda os limites racio- 
nais e metodológicos da proporcionalidade.

O Poder Judiciário não possui atribuição legal de formulador, gestor ou implementador de políticas públicas, tarefa afeta à competência dos outros poderes. A intervenção do Poder Judiciário, impondo obrigação de fazer ao administrador público nas questões prisionais, deve ser complementar e esporádica, atingindo somente os casos em que esteja presente a violação ao conteúdo essencial do princípio da dignidade da pessoa humana.

No mesmo sentido, a decisão judicial para ser efetiva deve considerar que as providências determinadas demandam tempo para serem executadas. $\mathrm{O}$ administrador público, mesmo diante de determinação judicial de execução de obra, não está autorizado a dispensar as exigências legais do devido processo licitatório. Estes procedimentos demandam tempo, que dependerá das características da obra a ser executada, do volume de recursos financeiros necessários e da modalidade licitatória indicada.

Dessa forma, a atuação do Poder Judiciário no controle de políticas públicas direcionadas às cadeias públicas somente será legítima se cumprir os requisitos legais. Como consequência a sentença deve ser fundamentada racionalmente, consignando em que ponto o caso em discussão viola o "mínimo existencial" do princípio da dignidade da pessoa humana, determinando somente as providências estritamente necessárias para a correção do problema. Não se pode deixar de conceder tempo suficiente para o administrador público executar as medidas necessárias.

\section{CONSIDERAÇÕES FINAIS}

Restou evidenciado no presente trabalho que a tendência das decisões do Poder Judiciário em relação aos estabelecimentos prisionais é seguir a teoria substancialista, ou seja, realizar intervenções supletivas em políticas públicas sempre que o princípio da dignidade da pessoa humana for violado em seu conteúdo mínimo.

O sistema prisional brasileiro está muito distante de garantir os direitos dos reclusos, com recorrentes violações às suas garantias legais e constitucionais. A estrutura física dos estabelecimentos prisionais, em geral, é caótica, necessitando de reformas urgentes. Além disso, a insuficiência de vagas leva a superlotações e submetem os reclusos a condições degradantes.

Mesmo diante deste contexto a jurisprudência resistia em reconhecer a necessidade do Poder Judiciário intervir nas questões mais graves. No entanto, este entendimento foi modificado por uma decisão do Supremo Tribunal Federal que reconheceu a necessidade de intervenção no poder discricionário do 
administrador público. Décadas de abandono e irresponsabilidade dos poderes constituídos levaram a uma situação em que a intervenção judicial se revela extremamente necessária.

\section{REFERÊNCIAS}

ASSIS, Rafael Damasceno de. A Realidade Atual do Sistema Penitenciário Brasileiro. Revista CEJ, Brasília, Ano XI, n. 39, p. 74-78, out./dez. 2007.

BARCELLOS, Ana Paula de. A eficácia jurídica dos princípios constitucionais: o princípio da dignidade da pessoa humana. $3^{\mathrm{a}}$ ed. Rio de Janeiro: Renovar, 2011.

. O Mínimo Existencial e Algumas Fundamentações: John Rawls, Michael Walzer e Robert Alexy. In. Ricardo Lobo Torres (Org.) Legitimação dos Direitos Humanos. Rio de Janeiro: Renovar, 2002.

BARROSO, Luís Roberto. Judicialização, Ativismo Judicial e Legitimidade Democrática. Anuário Iberoamericano de Justicia Constitucional, Madrid, n. 13, p. 17-32, 2009.

BRASIL. Constituição (1988). Constituição: República Federativa do Brasil. Brasília, DF: Senado Federal, 1988.

DWORKIN, R. Uma Questão de Princípios. [Trad. Luis Carlos Borges]. São Paulo: Martins Fontes, 2005.

FARIAS, Rachel Nunes de Carvalho. O Ativismo Judicial e a Ingerência do Poder Judiciário na Escolha de Políticas Públicas. Revista dos Tribunais Nordeste, São Paulo, v. 7, p. 127-150, set./out. 2014.

FAZIO, Cesar Cipriano de. Panorama Sobre Ativismo Judicial e a Judicialização da Política no Direito Brasileiro. Revista dos Tribunais, São Paulo, v. 939, p. 109-126, jan. 2014.

PÚBLICA, Forum Brasileiro de. Anuário do Fórum Brasileiro de Segurança Pública. São Paulo, 2015.

JUSTIÇA, Conselho Nacional de. Banco Nacional de Mandados de Prisão. Disponível em http://www.cnj.jus.br/bnmp/\#/relatorio, acessado em 14 de abril de 2016. 
PARANÁ, Fundo Penitenciário do. Relatório Circunstanciado. Disponível em: http:// www.depen.pr.gov.br/arquivos/File/Relatoriocircunstanciado2014. pdf. Acessado em 15 de abril de 2016.

SILVA, Cesar Sebastião da. Controle Judicial das Políticas Públicas de Segurança Pública. 2013. 185f. Dissertação (Mestrado em Direito Processual e Cidadania) - Universidade Paranaense - UNIPAR, Umuarama.

SOUZA, Celina. Políticas Públicas: Uma Revisão da Literatura. Sociologias, Porto Alegre, ano 8, n. 16, p. 20-45, jul./dez. 2006.

TEIXEIRA, Anderson Vichinkeski. Ativismo Judicial: nos limites entre a racionalidade jurídica e decisão política. Revista Direito GV, São Paulo, 8, p. 37-58, jan./jun. 2012.

\section{JUDICIAL CONTROL OF PUBLIC POLICIES: INTERVENTION IN PUBLIC PRISONS}

ABSTRACT: This article analyzes the possibility of intervention by the Judiciary in the implementation of public policies to correct the serious problems that affect public prisons. Thus, the jurisprudence behavior on the subject is analyzed, establishing the necessary conditions to authorize such judicial intervention.

KEYWORDS: Judicial Control; Prison; Public Policies.

\section{CONTROL JUDICIAL DE POLÍTICAS PÚBLICAS: INTERDICIÓN DE CADENAS PÚBLICAS}

RESUMEN: El presente artículo analiza la posibilidad de intervención del Poder Judicial en la implementación de políticas públicas para la corrección de los graves problemas que afectan a las cadenas públicas. Así, se estudia el comportamiento de la jurisprudencia acerca del tema y establece las condiciones necesarias que autorizan la intervención judicial.

PALABRAS CLAVE: Control Judicial; Establecimiento Carcelario; Políticas Públicas. 